\title{
НОВЫЕ НАПРАВЛЕНИЯ, ФОРМЫ И ТЕХНОЛОГИИ ВЫСШЕГО ОБРАЗОВАНИЯ В СВЕТЕ ПРАВОВОГО РЕГУЛИРОВАНИЯ ИНТЕГРАЦИИ И ЦИФРОВОЙ ТРАНСФОРМАЦИИ"
}

\author{
(c) 2019 Щукина Татьяна Владимировна \\ доктор юридических наук, доцент, заведующая кафедрой прикладного права \\ Российский Технологический Университет - МИРЭА, Россия, Москва \\ профессор кафедры административного и финансового права \\ Липецкий филиал РАНХиГС, Россия, Липецк
}

Предметом настоящей статьи выступает исследование новых направлений, форм и технологий высшего образования при экспорте российского высшего образования за рубеж; рассмотрение правового регулирования экспорта высшего образования. Тема статьи отражает вопросы трансформации современной системы высшего образования с точки зрения международной интеграции образовательных программ; новых направлений правового регулирования и разработки федеральных образовательных стандартов высшего образования в условиях цифровизации. Целью настоящей статьи являются выявление на современном этапе трендов развития высшего образования, места и роли государства и университетов в этом процессе. Методологию данной работы составили сравнительный, формально-юридический, аналитический методы. Результаты работы - это формулирование особенностей правового регулирования и организации экспорта российского высшего образования. Область применения результатов работы включает в себя систему управления высшим образованием. Выводы исследования могут быть использованы для дальнейшего совершенствования правовой регламентации и практики организации высшего образования в России.

Ключевые слова: новое правовое регулирование экспорта высшего образования, инновационные формы и технологии высшего образования, цифровая трансформация.

Изменение траекторий образования, включая высшее образование, намечается уже в настоящее время. Об этом свидетельствует целый комплекс факторов: 1) мнения ученых (П. Лукша, Ч. Фейдл, М. Бялик, Б. Триллинг); 2) новые мегатренды развития российского образования и в мире: геополитические, демографические, технологические тренды; программы европейского обмена Erasmus+ (Доклад Global Education Futures «Навыки будущего», Доклад BCG «Россия 2025: от кадров к талантам»); 3) применение обновленных технологий в образовании (онлайн технологии, product-технологии, технологии дизайн-мышления); 4) появление современных новых профессий (продакт-менеджер, архитектор медоборудования) и появление междисциплинарных специальностей; 5) увеличение спроса на индивидуальное образование и индивидуальные траектории образования ввиду применения в процессе производства и трудовой деятельности искусственного интеллекта;
6) необходимость обучения на протяжении всей жизни.

Все эти факторы приводят к дроблению образовательных программ на модули, дальнейшему развитию цифрового образования в дистанционных форматах, снижению физической мобильности студентов и смещению экспорта образования к использованию «облачных технологий» (виртуальная мобильность). Отметим, что новое видение известной в ЕС программы ERASMUS+ предполагает внедрение смешанной мобильности, которая выражается: а) в сокращении времени пребывания в университете и замене его виртуальными компонентами; б) в партнерском онлайн обучении и обмене командами; в) в изучении смешанных интенсивных образовательных программ (онлайн курсы и задания); г) в междисциплинарном характере образовательных программ; д) в гибких ученых планах.

Получается, в итоге, более персонализиро-

\footnotetext{
* Статья подготовлена в рамках гранта РФФИ 19-011-00959 «Моделирование экспорта высшего образования в рамках новых стратегий публичного управления в Российской Федерации» 2019-2021 г.г.
} 
ванное обучение, краткосрочное (модульное), охватывающее несколько компетенций и предполагающее сокращенный учебный план. И сам университет как монолитное социально-культурное явление постепенно превратится в сетевую межрегиональную структуру. Переход к сертификации в сочетании с непрерывным образованием, сокращением учебных планов и уменьшением значимости дипломов для работодателей также может быть реальностью в недалеком будущем. Смещение акцентов с получения квалификации (степени) согласно диплому об образовании на обретение компетенций, выражающихся в умениях и навыках, сводит существование высшего образования в современном понимании к нулю.

Снижение студенческой мобильности из-за расширения применения дистанционного, электронного обучения уменьшит поток иностранных студентов в университеты Великобритании, США, Австралии и других стран, где в настоящий момент эффективно действует бизнес-модель образования на основе интернационализации [1]. Ввиду этого формат деятельности университетов и собственно высшего образования должен разумно трансформироваться без ущерба социальному значению исследований и обучения, учебного заведения и отношения общества к вузам.

Концепция «набор индивидуальных компетенций, а не диплом» вызывает серьезные размышления и недоумение. Подобный футуристический замысел направлен на удешевление стоимости обучения, формирование обучения для всех с последующей массовостью обучения определенным наборам компетенций. Если это будет первым высшим образованием, то оно мало отличается от среднего профессионального образования, причем в худшем варианте. Например, в образовательной программе среднего профессионального образования предполагается наличие до 20 компетенций (общие, профессиональные компетенции) [2], а для работодателя на данный момент, например, достаточно всего 5 профессиональных компетенций. Следовательно, «лишние компетенции» останутся без внимания и это будут в основном общекультурные компетенции (соблюдать основы здорового образа жизни, требования охраны труда; деловой этикет, культуру и психологические основы общения, нормы и правила поведения).

Классическое образование, включая высшее, станет недоступным и элитарным.

Думается, должен быть набор компетенций, подтвержденный дипломом, а не сертификатом. В последнем варианте это уже будет не высшее образование, а дополнительное профессиональное образование. Ведь непрерывное образование в течение всей жизни превращает образовательный процесс в перманентное, более или менее системное овладение определенным набором компетенций для этапа работы в 3-4 года, который необходим для развития бизнеса или реализации проекта. Такое видение высшего образования приемлемо для негосударственного сектора, а профессиональная служебная деятельность на государственной гражданской и правоохранительной службе? Для государственного служащего овладение наборов компетенций - это превращение слуги государства в обычного наемного работника. В данном аспекте смещение акцентов с получения квалификации (степени) согласно диплому об образовании на обретение компетенций является весьма сомнительной концепцией в системе государственной службы. Тоже относится к медицинскому и техническому образованию.

Зарубежные страны разделяют получение высшего образования, на официальное, то есть подразумевающее обучение на полной аккредитованной образовательной программе, и на формальное, которое длится в течение всей жизни человека. Иными словами - курсы повышения квалификации или дополнительное образование для стимулирования личностного развития, улучшения здоровья и общего качества жизни [3]. Это - альтернатива, дополнение к официальному образованию (короткие курсы, практикумы или семинары), формирующие некую квалификацию.

В Российской Федерации государство должно продвигать политику по созданию условий для получения первого высшего образования по национальным государственным образовательным стандартам (пусть они могут быть интегрированы в определенной части с модулями международных образовательных программам). Последующее образование как набор компетенций должно представлять собой гибкую образовательную краткосрочную модульную программу, рассчитанную на нормативный срок обучения в 1 год. Но под эти образовательные программы отсутствуют федеральные государственные образовательные стандарты. И это 
проблема нормативно-правового регулирования, а профессиональные стандарты не всегда отвечают на индивидуальные запросы обучающегося. Как правило, в профессиональных стандартах практически отсутствуют междисциплинарные компетенции. При непрерывном обучении речь о наборе междисциплинарных компетенций, где их набор меняться в течение 3-4 лет. Не стоит превращать разработку и реализацию подобных образовательных программ высшего образования в программы дополнительного профессионального образования с последующей выдачей, по сути, образовательного сертификата.

Возникает вопрос о направлениях развития образовательных программ высшего образования, особенно в связи с появлением цифровых компетенций. Как правило, круг данных компетенций не предусмотрен в государственных образовательных стандартах по определенному направлению подготовки или специальности. Таки образом, овладение новыми компетенциями должно осуществляться студентами в рамках курсов minor учебного плана (речь идет о гибком учебном плане), дополнительно к изучаемой образовательной программе. В противном случае, выпускники программы окажутся слабо конкурентоспособными на действующем рынке труда; претендующими на аутсайдерские позиции и по уровню заработной платы, и по возможности самореализации и выстраиванию карьеры. Например, обучающийся по классическому направлению подготовки «Юриспруденция» (бакалавр, магистр) не сможет претендовать на эксклюзивные должности с уровнем заработной платы от 60 до 150 тыс.рублей (координатор работы сообществ, директор проекта), т.к. как не обладает профессиональными знаниями и навыками в профессиональных областях: внедрение IT-решений, программирование, знание иностранного языка на уровне сертификации и др. Относительно программирования, необходимо целостное представление работы с IT-технологиями в конкретной сфере управления и бизнеса. Кроме того, навыки креативного мышления (дизайн-мышления) очень востребованы в бизнесе, без них роль руководителя просто не воспринимается работодателем. Но этим навыкам обучают не в государственных университетах, а только в корпоративных университетах (Сбербанк и др.), лабораториях под эгидой IT и медиа корпораций (Фейсбук и т.д.). Это - меж- дисциплинарные компетенции.

Компетенции, равно как и их набор, необходимый для работодателя, изменяются очень быстро, в течение 2-3 лет, а обычный курс образовательной программы бакалавриата рассчитан на 4 года. Именно, в этом кроется основной первый риск формализации государственных образовательных стандартов и современной системы обучения в целом. Изменения компетенций и навыков усилят значение профессионального опыта, который обретут выпускники по окончанию образовательной программы. Ввиду этого необходимо модернизировать формы проведения практик, расширить перечень базовых кафедр в университетах, формировать гибкие учебные планы.

Второй риск - нельзя допустить вытеснение фундаментальных теоретических знаний из пространства обучения на программах высшего образования, т.к. теоретическая основа науки определяет ее практическое применение.

Третий риск - определение истинности и фундаментальности теоретических знаний, которые буду передаваться через онлайн платформы. Это потребует определенного правового регулирования (сертификация, верификация субъекта знаний и субъекта, обеспечивающего трансляцию и тиражирование информации). Следовательно, перманентная трансформация компетенций и связанных с ними навыков у обучающихся, изменение требований работодателей определяет необходимость для образовательных организаций постоянного мониторинга тенденций в высшем образовании и рынке труда. Формировать дополнительно обширную систему курсов повышения квалификации и программ профессиональной переподготовки в различных областях науки и техники, которые помогут сформировать новые профессиональные навыки, компетенции, не предусмотренные стандартами выбранной образовательной программы.

Одновременно получению новых знаний и навыков будут способствовать новые структуры университетов (лаборатории, инновационные школы, центры правовой помощи и т.п.). Академическая мобильность и реализация экспорта образования определенно будет способствовать обретению новых компетенций и навыков у обучающихся (летние и зимние международные школы, совместное обучение российских и зарубежных студентов, обмен знаниями и опытом 
НПР).

В качестве образовательных технологий, позволяющих минимизировать вышеперечисленные риски и реализовать указанные новые направления в образовательном процессе, могут выступить:

- разумное сочетание онлайн лекций, семинаров с подобными форматами, но уже в личном общении;

- технологии дизайн - мышления (профессиональные игры, тренинги, хакатоны); использование новых IT-технологий (веб-дизайн, большие данные и др.);

- технологии стратегии создания идеи проекта, его реализации и получения результата (product-технологии).

Недопустимо, особенно региональные университеты, превратить в комбинаты по переподготовке выпускников с множеством меняющихся образовательных программ, в большей степени индивидуальных. Это будет не очень выгодно с точки зрения окупаемости для университета, так как придется учить каждого и по разным наборам компетенций. Тогда научно-педагогический состав университета превратится в конвейер по разработке и по обучению конкретным компетенциям, и одновременно появятся, так называемые «сборщики программ», которые будут разработчиками разнообразных модульных программ, рассчитанных на возможные запросы клиентов по индивидуаль- ным компетенциям.

Такое «высшее образование» будет с точки зрения культуры, коммуникаций, кругозора и стратегического, креативного мышления просто ничтожным. Воспитательная, духовная и патриотическая, национальная роль высшего образования будет утрачена. Социально-духовная опора государства - нивелирована. Университет станет «швейной мастерской» по пошиву специалистов с индивидуальным набором компетенций. Социальное, общественное значение высшего образования и университета сведется к минимуму: наличие навыков и оперативных знаний. Знания в масштабе освоения культуры, искусства, инновационных изменений, формирующих стратегически мыслящего специалиста, будут недоступны. Для Российской Федерации этот вариант развития образования не подходит. Наше государство может предоставить всем гражданам первое высшее образование в рамках национальных образовательных стандартов с широким набором компетенций. А Центры компетенций обеспечат разработку типовых наборов компетенций с учетом региональной специфики, скоординируют реализацию подобных гибких образовательных программ в университетах региона или сети регионов. Подобный подход позволит сохранить региональные университеты как основу и опору общественной жизни и государственной власти.

\section{Библиографический список}

1. Higher Education, Benchmarking Higher Education System Performance - 2019. OECD. https: // doi.org/ 10.1787/ be5514d7-en

2. Об утверждении федерального государственного образовательного стандарта среднего профессионального образования по специальности 40.02.01 Право и организация социального обеспечения: приказ Министерства образования и науки РФ от 12 мая 2014 г. N508 // Рос. газ. 2014. 13 ноября.

3. Higher Education, Benchmarking Higher Education System Performance - 2019. OECD. https:// doi.org/ 10.1787/ be5514d7-en 